BMJ Open Sport \& Exercise Medicine

\title{
Can clinicians and scientists explain and prevent unexplained underperformance syndrome in elite athletes: an interdisciplinary perspective and 2016 update
}

\author{
Nathan A Lewis, ${ }^{1,2,3}$ Dave Collins, ${ }^{4,5}$ Charles R Pedlar, ${ }^{1,3}$ John P Rogers ${ }^{1,6}$
}

To cite: Lewis NA, Collins D, Pedlar CR, et al. Can clinicians and scientists explain and prevent unexplained underperformance syndrome in elite athletes: an interdisciplinary perspective and 2016 update. BMJ Open Sport Exerc Med 2015;1: e000063. doi:10.1136/ bmjsem-2015-000063

- Prepublication history for this paper is available online. To view these files please visit the journal online (http://dx.doi.org/10.1136/ bmjsem-2015-000063).

Accepted 28 October 2015

CrossMark

For numbered affiliations see end of article.

Correspondence to

Nathan A Lewis;

nathan.lewis@orreco.com

\section{ABSTRACT}

The coach and interdisciplinary sports science and medicine team strive to continually progress the athlete's performance year on year. In structuring training programmes, coaches and scientists plan distinct periods of progressive overload coupled with recovery for anticipated performances to be delivered on fixed dates of competition in the calendar year. Peaking at major championships is a challenge, and training capacity highly individualised, with fine margins between the training dose necessary for adaptation and that which elicits maladaptation at the elite level. As such, optimising adaptation is key to effective preparation. Notably, however, many factors (eg, health, nutrition, sleep, training experience, psychosocial factors) play an essential part in moderating the processes of adaptation to exercise and environmental stressors, for example, heat, altitude; processes which can often fail or be limited. In the UK, the term unexplained underperformance syndrome (UUPS) has been adopted, in contrast to the more commonly referenced term overtraining syndrome, to describe a significant episode of underperformance with persistent fatigue, that is, maladaptation. This construct, UUPS, reflects the complexity of the syndrome, the multifactorial aetiology, and that 'overtraining' or an imbalance between training load and recovery may not be the primary cause for underperformance. UUPS draws on the distinction that a decline in performance represents the universal feature. In our review, we provide a practitionerfocused perspective, proposing that causative factors can be identified and UUPS explained, through an interdisciplinary approach (ie, medicine, nutrition, physiology, psychology) to sports science and medicine delivery, monitoring, and data interpretation and analysis.

\section{INTRODUCTION}

Over the past decade an expert group from Europe and the USA has provided joint consensus statements on the topic of

\section{What are the new findings}

- Unexplained underperformance syndrome (UUPS) can be prevented, and retrospectively explained should it present, through the longitudinal collection of athlete data via comprehensive, structured monitoring programmes.

- Periodisation and individualisation of the athlete's nutritional requirements are crucial in preventing underperformance syndrome; athlete monitoring is required to do this effectively.

- Old concepts of homoeostasis with regard to stress must be modified against each individual's perceptions of the stressor and how well equipped $s /$ he is to cope with it.

- The use of the term overtraining syndrome (OTS), rather than UUPS, can be unhelpful when engaging with the athlete and coach. OTS can lead both to misapprehend training as the sole cause and the problem (which in itself can encourage blame), thus diverting attention and focus from what are often the key issue/s.

overtraining syndrome (OTS). ${ }^{2}$ In the UK, the term unexplained underperformance syndrome (UUPS) has been adopted. ${ }^{3}{ }^{4}$ For the purpose of this review, UUPS will be used throughout as opposed to OTS. The term UUPS reflects the complex nature of the condition, the multifactorial aetiology, and that an imbalance between training load and recovery may not be the primary reason for the presentation, for example, a significant life stressor, perceived imbalance or poor nutrition may be another factor that leads/contributes to maladaptation. ${ }^{2} 5$ Indeed, no single factor has been identified as the sole cause for UUPS. ${ }^{12} 6$ Thus, while the universal feature and a prerequisite for the diagnosis of UUPS is an unexpected decline in performance ${ }^{2} 7$ despite a period 
of extended rest, causation requires a broader perspective.

The wide variation in symptoms on presentation adds to the complexity of the condition, with no absolute consistencies, other than a heightened state of fatigue and increased perception of effort with training. Mood disturbances, decreased motivation, weight loss, loss of appetite, increased incidence of infection and sleep disturbances are all variously reported components of the condition. ${ }^{128-10}$ As part of the diagnostic work up, significant organic disease must be excluded (eg, cardiac or endocrine diseases), along with infectious diseases, allergies, eating disorders, depression and nutritional deficiencies such as energy, carbohydrate/protein intake, iron, vitamin D and magnesium. ${ }^{2-4} 10$ Indeed, the diagnosis of UUPS can only conclusively be made retrospectively, once the recovery time is known. Moreover, expert groups have stated that the symptoms and physiological responses are highly variable and in many instances, individual. ${ }^{2} 510$ The latter point emphasises the importance of longitudinal monitoring of individual athletes, thereby increasing the potential for early identification and signs of maladaptation. In fact, the individual presentation of the condition emphasises the challenges faced by researchers using conventional statistical approaches to identify significant differences between UUPS versus healthy athletes for a given physiological or biochemical variable. In elites, an informed case study approach may well be the best means for diagnosing, understanding and countering this condition.

In elite athletes, the prevalence of UUPS/OTS may be high, ${ }^{1} \quad 2 \quad 556$ particularly if assessing across athletic careers. In elite middle distance runners, Morgan et al ${ }^{11}$ found that $64 \%$ of male athletes and $60 \%$ of female athletes reported experiencing UUPS/OTS at some point in their athletic careers, while a recent study across 26 sports including 129 elite Swiss athletes estimated a career prevalence rate of $30 \% .^{6}$ An analysis of 257 British National and Olympic elite athletes across a single season reported a prevalence of UUPS/OTS in $15-35 \%$ of men, and $4-15 \%$ of women. ${ }^{7}$ Notably, athletes in individual sports may be at even greater risk of non-functional over-reaching (NFOR) and OTS as a result of greater weekly training hours, ${ }^{8}{ }^{10}$ as are those competing at a higher level. ${ }^{10}$

A 2016 review of this topic from the point of view of the applied practitioner and clinician is both warranted and timely, building on the comprehensive consensus statements of Meeusen et $a l^{2}$ because it is both realistic and practical to prevent the development of UUPS. Indeed, only the implementation of well-structured longitudinal monitoring programmes encompassing biomarkers, physiological and physical measures, in tandem with wellness and readiness to train tools that draw on an integrated interdisciplinary approach to data interpretation and athlete management can achieve this. Consequently, we propose that UUPS can only be prevented and causative factors identified, and thus underperformance explained should it occur, through the collection and interdisciplinary analysis of athlete's data. Hence, the title of our review from unexplained underperformance to underperformance explained. To support our argument, and to facilitate practitioner application of our key messages, we now provide a disciplinary breakdown of key factors, before returning to an interdisciplinary integration at the end of the paper.

\section{A sport physician's perspective}

Reduced performance and fatigue is a common presentation for sports physicians, particularly when working with endurance athletes. ${ }^{12}$ Notably, however, it can be diagnostically challenging to distinguish between the normal physiological spectrum of fatigue/functional over-reaching (OR) in an athlete with high training volumes, and the multitude of medical conditions that can present in a similar way. With persistent fatigue and underperformance in athletes lasting 2 weeks or more despite adequate rest and recovery, many different causes should be considered. Any significant medical problem can contribute to underperformance but the most common causes seen in a younger athletic population are outlined in box 1 along with less common causes in box $2^{12}$

Once the underperformance has been established, athletes should be assessed by a sports physician in order to promptly diagnose and treat any underlying medical causes. Given the breadth of possibilities, the initial consultation may be lengthy, with many areas covered and initial investigations undertaken. There may be one specific trigger for fatigue and underperformance, but more

\section{Box 1 Common causes for athlete underperformance}

Musculoskeletal injuries, for example, trauma, tendinopathy, hamstring tears, bone stress

Physiological: functional over-reaching, jet lag, insufficient sleep, pregnancy, heat, cold, altitude, dehydration

Infection, for example, upper and lower respiratory tract infections, flu-like illness, traveller's diarrhoea/gastroenteritis, glandular fever (Epstein-Barr virus)

Asthma

Allergies/hay fever

Nutritional deficiencies: protein, carbohydrate, minerals (eg, iron, magnesium), vitamins (eg, D), Relative Energy Deficiency in Sport ${ }^{20} 21$

Iron deficiency (+/- anaemia), for example, coeliac disease, vegetarians, altitude, menorrhagia, non-steroidal anti-inflammatory drug abuse

Concussion

Stress, anxiety, depression, eating disorders

Non-functional over-reaching and unexplained underperformance syndrome 
Box 2 Less common causes for athlete

underperformance

Endocrine disorders: diabetes, thyroid, hypothalamic-pituitaryadrenal or gonadal or ovarian dysfunction

Cardiovascular disorders: venous thromboembolism, coronary artery disease, inherited cardiac disease, arrhythmias, myocarditis, arterial insufficiency (eg, gut or limb ischaemia)

Chronic infections, for example, malaria, tuberculosis, hepatitis, HIV, cytomegalovirus

Inflammatory conditions: arthritis/spondyloarthropathy, inflammatory bowel disease

Cancer

\section{Chronic fatigue syndrome}

Neurological/neuromuscular disorders, for example, chronic pain, acquired training intolerance, myopathies, multiple sclerosis

Drugs, for example, $\beta$-blockers, antihistamines, central nervous system acting, doping, alcohol/recreational use

commonly, there is a combination of several contributing factors, for example, high training volumes with inadequate recovery; environmental conditions (altitude,

\section{Box 3 What to address within the athlete's history}

Fatigue: onset, duration, severity, possible triggers, recent travel

Any recent illness or associated symptoms

Underperformance: quantify degree and duration of impairment.

Recent training and competition data. Review any physiology data available, for example, training heart rates

Training: type(s), volume, frequency, intensity, location, monotony, goals, perception of effort. Review the athletes training diary for any recent adjustments

Sleep: quantity, quality, insomnia, daytime naps

Psychological screen: presence of mood disturbances and the duration. Stress, anxiety, appetite, libido. Disordered eating

Medical history: injuries, illness, surgery

Menstrual history: menarche, contraception, last period, frequency of periods, presence of menorrhagia

Drug history and allergies

Nutrition screen: typical daily food and fluid intake, timing, recent changes, dietary exclusions, use of supplements

Family history - sudden cardiac death, atopy, autoimmune or endocrine disorders

Social history: work, examinations, financial pressures, support structure around relationships, family and friend

Systematic questioning to screen for cardiovascular, respiratory, gastrointestinal, genitourinary, sexual health, neurological, ear nose and throat, oral health

Specifically ask about fever, cough, wheeze, sore throat, swollen glands, muscle pains, postural dizziness, loose stools, repeated infections suggestive of immunosuppression, weight loss/gain, night sweats, exertional symptoms, pain
Box 4 Physical examination to be completed as part of the athlete consultation

General: body mass index, temperature, jaundice, anaemia, lymphadenopathy, hydration status, oedema, muscle tenderness, musculoskeletal

Cardiovascular system pulse rate and rhythm, blood pressure (lying and standing), heart sounds

Respiratory system: respiratory rate, auscultation, peak flow rate, oxygen saturations

Ear nose and throat: rhinitis, throat infection

Gastrointestinal: abdomen such as tenderness, masses, hepatosplenomegaly

Neuromuscular: muscle tone and strength, reflexes, sensation upper and lower limbs

Other targeted examination as directed by the history

heat); external stresses related to work, studies or relationships; recent illness or viral infection; nutritional deficits. Clearly, significant medical problems need to be excluded through a detailed history with systematic questioning (box 3), a targeted physical examination (box 4) and appropriate baseline (box 5) and targeted investigations at the clinician's discretion (box 6).

If significant medical causes have been excluded, a diagnosis of UUPS can be made if the athlete continues to underperform in conjunction with fatigue despite recovery and rest. There are often identifiable medical causes and thus the underperformance is explainable and treatable, and a diagnosis of UUPS is not appropriate. To complicate matters, in many cases, there are confounding factors such as recent viral illness, psychosocial factors, nutritional deficiencies, unfamiliar environmental conditions and sudden increases in training that contribute to the development of UUPS; part of the management will involve addressing these underlying issues. Accordingly, athletes with UUPS should be referred for assessment by a suitable qualified sports nutritionist/dietitian and an exercise physiologist.

Box 5 Routine baseline investigations for the athlete with underperformance and fatigue

Full blood count with differential white cell count

Serum ferritin

Vitamin $D\left(D_{2}\right.$ and $\left.D_{3}\right)$

Biochemistry; renal function and electrolytes, liver function tests, bone profile, creatine kinase, glucose, $\mathrm{C}$ reactive protein

Thyroid function tests

Red blood cell magnesium

Epstein-Barr virus serology

Urine dipstick-specific gravity, glucose, blood, protein, leucocytes

ECG 
Box 6 Further investigations to consider in cases of unexplained underperformance syndrome (UUPS)

Infection: malaria screen, viral studies, for example, cytomegalovirus serology, hepatitis, HIV, lyme disease, stool samples for microscopy, culture, sensitivity, ova, cysts and parasites

Endocrine: Glycated haemoglobin, hormone studies, for example, follicle-stimulating hormone, luteinising hormone, oestradiol, free and total testosterone, serum hormone-binding globulin, prolactin, cortisol, ACTH/synacthen test, parathyroid hormone, triiodothyronine

Nutrition: vitamin $B_{12}$, red cell folate, coeliac screen (if iron deficient), trace elements (ie, zinc, copper)

Chest $\mathrm{X}$-ray, spirometry, allergy testing

Cardiopulmonary exercise testing and echocardiogram

Specialist referral where indicated, for example, endocrinology

If UUPS diagnosed, then a comprehensive nutritional and physiology assessment by sports nutritionist and physiologist

Where there are underlying psychological issues (and this should be the default rather than the exception position), the athlete should be referred early to a sport psychologist or other mental health professional for further assessment and treatment. After this return to training and competition, should be guided by the interdisciplinary team, with clear communication with the athlete and their coach on time scales, volume, intensity and frequency of training. Regular review and feedback using a variety of longitudinal monitoring tools is ideal in the progression back to full training. ${ }^{13}{ }^{14}$

\section{A performance nutrition scientist's perspective}

Meeusen $e t a l^{2}$ highlight a number of nutritional considerations in the prevention of UUPS giving priority to the importance of carbohydrate, energy and fluid intake for the prevention of glycogen depletion, a negative energy balance (EB) and dehydration. ${ }^{2}$ They address the importance of adjusting carbohydrate intake for periods of intensified training to prevent glycogen depletion and the resulting metabolic, endocrine, mood and performance disturbances that can accrue and are observed in over-reached states. ${ }^{15}{ }^{16}$ However, there are other nutritional factors which warrant consideration in the prevention and management of UUPS.

For example, a negative EB is deemed to be a risk factor for UUPS. However, it is important to recognise that a negative EB per se is not detrimental to adaption and performance in athletes, although it is likely to increase fatigue and ratings of perceived exertion (RPE). Nor is it necessary for the athlete to be in a state of EB for improvements in athletic performance. ${ }^{2}$ 17-19 Athletes will go through training periods with reduced energy availability (EA) and negative EB by a process of periodisation, with the manipulation of macronutrient intake catered for in order to optimise body composition and performance. Significantly, however, a sustained chronic lack of sufficient EA leads to a decline in bioenergetic hormones, poor recovery and maladaptation, placing the athlete at risk of both injury and UUPS. $^{2} 17{ }^{20}{ }^{21}$ For example, Vanheest $e t$ al ${ }^{17}$ directly linked EA and performance in elite athletes. The athletes in whom performance declined across the 12 weeks by $\sim 8 \%$ were in a negative $\mathrm{EB}$ for the entire 12-week period (low EA; $10-12 \mathrm{kcal} / \mathrm{kg}$ fat-free mass (FFM)). In contrast, the athletes in which performance improved by $\sim 8 \%$ after 12 weeks, experienced $\sim 8-10$ weeks of a negative $\mathrm{EB}$, and were in $\mathrm{EB}$ at weeks 2 and 4 only (sufficient EA; $30-37 \mathrm{kcal} / \mathrm{kg}$ FFM). It should also be noted that performance was only adversely affected in the low EA group after 6 weeks of sustained low EA. Critically, the training volume and intensity were increased after week 4. This unique study highlights the importance of sufficient EA and periodised nutrition around intensified training periods to facilitate recovery and adaptation, and the prevention of underperformance. Moreover, a sustained chronic period of low EA is sufficient to induce a state of explained underperformance in endurance athletes, and highlights the importance of well-structured and designed monitoring programmes in athletes to prevent unexplained underperformance (UUPS). It is our experience that the use of bioenergetics hormones (eg, free triiodothyronine) can aid the prescription of nutritional support around the training response (stimulus and recovery) in elite healthy athletes.

In this regard, there is increasing interest surrounding the athlete exercising with low carbohydrate availability on muscle physiology and indeed performance, referred to as train low, or fasted training and of late, sleep low. ${ }^{22} 23$ The latter approach may confer a greater risk for UUPS given the crucial role for sleep in athletic performance, ${ }^{24}$ dietary carbohydrates for sleep onset ${ }^{25}$ and calorie intake for sleep quality. ${ }^{24}$ However, increasing dietary protein may serve to attenuate the risk, given the capacity for protein to enhance sleep quality ${ }^{24}$ and recovery. ${ }^{26}$ Although there are physiological benefits to the athlete performing structured training sessions in the presence of low carbohydrate availability, ${ }^{27-32}$ there are risks associated with such practices. Indeed, such sessions should be planned in to the athletes training cycle along with appropriately structured monitoring (physiological, biochemical, hormonal, immunological, psychological, performance), and be relevant to the athlete's physiological development (eg, training age), training goals and performance requirements. ${ }^{32}$ The practitioner, or athlete self-imposing a restricted carbohydrate diet without monitoring and guidance, with a view to reducing fat mass or enhancing muscle oxidative capacity, for example, may cause chronic low EA and this carries a high risk of maladaptation, infection, reduced performance and UUPS. ${ }^{2}{ }^{17} 20$ Exercising with low carbohydrate availability will increase inflammatory cytokine release, ${ }^{33}$ and it has been proposed that excessive cytokine release and inflammatory state during and postexercise may lead to UUPS. ${ }^{34}$ The cytokine, 
interleukin-6 (IL-6), previously referred to as a 'fatigueogen', increases under conditions of low carbohydrate availability. ${ }^{33} 35$ Indeed, IL-6 has been implicated in fatigue and UUPS, ${ }^{33}$ with elevated concentrations reported to impair exercise performance. ${ }^{36}$ Furthermore, altered cytokine responses to exercise (eg, elevated IL-6) have been observed in illness prone athletes, ${ }^{37}$ and athletes presenting with UUPS frequently report infective illnesses. ${ }^{34}$ Nutritional support for the immune system should be prioritised through intensified training and competition periods, especially in those athletes with a history, or at an increased risk of UUPS, for example, known psychological stress, illness prone athletes and junior athletes. It is beyond the scope of this paper to address the immune support of the elite athlete, which is comprehensively reviewed elsewhere. ${ }^{38}$ Finally, exercising with low muscle glycogen availability increases skeletal muscle breakdown, amino acid oxidation, serum and sweat nitrogen losses ${ }^{39} 40$ and lowers plasma glutamine concentrations; ${ }^{41}$ the latter an observation reported in chronically fatigued elite athletes. ${ }^{42} 43$

Adequate dietary protein is integral for health, immunity, adaptation and athletic performance, ${ }^{26} 4445$ with inadequate dietary protein reported in chronically fatigued athletes, ${ }^{43}$ and significant alterations in plasma amino acids observed in fatigued versus healthy athletes, that is, glutamine and glutamate. ${ }^{42} 4346-49$ In addition, increased dietary protein $(3 \mathrm{~g} / \mathrm{kg} /$ day $)$ intake during a period of overload training in endurance athletes has been shown to attenuate the decline in performance and increase in symptoms of stress. ${ }^{26}$ Furthermore, increasing dietary protein $(3 \mathrm{~g} / \mathrm{kg} /$ day $)$ during a 2-week block of high-intensity training in cyclists restored the exercise-induced leucocyte trafficking impairment, with fewer symptoms of upper respiratory tract infections. ${ }^{50}$ In accordance with the aforementioned studies in endurance training models of OR, additional protein in the form of amino acids served to attenuate decrements in performance and increases in muscle damage observed in high volume resistance training OR. ${ }^{51}$ Periodised adjustments to the athlete's protein intake may serve to modify the impact of intensified periods of training on measures of fatigue and immunity, and enhance performance outcomes. Indeed, it should be emphasised that the periodisation of nutritional support, consisting of adjustments to energy and macronutrients (eg, carbohydrate and protein) and micronutrient intakes around training phases (eg, iron, magnesium, vitamin D), and most crucially intensified training blocks, are a critical element of the successful optimisation of performance, and prevention of UUPS.

Inflammation, oxidative stress (OS) and alterations in redox homoeostasis (ARH) have been implicated in the pathophysiology of OTS, ${ }^{52-54}$ with ARH reported in athletes diagnosed with OTS. ${ }^{53}$ In chronic fatigue syndrome (CFS; a conditioned likened to OTS), OS is associated with the degree of fatigue at rest and postexercise, ${ }^{55-57}$ with several studies demonstrating increased OS in CFS versus healthy controls. ${ }^{56}{ }^{58-62}$ CFS can be said to represent the extreme end of the OTS continuum. In welltrained athletes, the short-term (2 weeks) restriction of fruit and vegetable intake (ie, low antioxidant diet), to just one-two servings per day, results in increased OS, exercise RPE and inflammation, albeit with no change in performance. ${ }^{63}{ }^{64}$ However, the lack of a significant change in performance may merely reflect the shortterm nature of the studies. Polyphenols, constituents of fruit and vegetables, have been shown to attenuate OS in athletes and reduce the inflammatory response to exercise, including IL-6, improve sleep duration and quality, and enhance skeletal muscle regeneration. ${ }^{65-69}$ It is interesting to speculate that a chronic lack of sufficient dietary fruits and vegetables (recognising the vast array of different chemicals present ${ }^{70}$ ) may lead to slower rates of skeletal muscle regeneration in the athlete, thus placing the athlete at greater risk of UUPS. It is known that the skeletal muscles of healthy endurance athletes display evidence of structural damage, while those endurance athletes diagnosed with acquired training intolerance (ie, UUPS) display significantly greater evidence still of skeletal muscle pathology. ${ }^{71}$ Vitamin E ( $\alpha$-tocopherol) is integral to skeletal muscle membrane repair ${ }^{72}$ with serum vitamin $\mathrm{E}$ inversely associated with muscle pain thresholds generated via electrical stimulation and fatigue in CFS and healthy controls. ${ }^{55}$ Low dietary intakes of vitamin $\mathrm{E}$ are reported in some athletes ${ }^{73}{ }^{74}$ but not others, ${ }^{75}$ with increased postexercise red blood cell haemolysis observed in female athletes with low fat intakes and reduced serum vitamin $\mathrm{E}$ concentrations. ${ }^{74} \mathrm{~A}$ relationship with red blood cell fragility and serum vitamin $\mathrm{E}$ was also reported in elite male swimmers. ${ }^{76}$ Increased skeletal muscle uptake of vitamin $\mathrm{E}$ and the carotenoid $\beta$-carotene occurs with exercise, ${ }^{77}$ and there is evidence for specific training methodologies (ie, 18 days of live-high-train-low) impacting negatively on elite athletes antioxidant status (eg, serum vitamin $\mathrm{E}$ and carotenoids) in some studies, ${ }^{78}{ }^{79}$ but not others $;{ }^{80}$ for a review see Lewis $e$ al. ${ }^{81}$

Environmental factors (eg, overseas training camp, altitude, heat stress) may influence the risk of UUPS through (1) enforced dietary changes coupled with added physiological stress such as increased training volume or competition; recognising short-term dietary omissions influence recovery and fatigue, and (2) combination of heat stress, dehydration and high-intensity exercise resulting in mucosal injury, gut permeability, and increased bacterial and inflammatory challenge and OS. $^{82} 83$ Notably, oxidants are implicated in ischaemia-induced gut injury and associated bacterial translocation, with antioxidants (ie, ascorbic acid) preventing exercise-induced endotoxaemia resulting from maximal exercise. ${ }^{83}$ Through our own observations (unpublished data), biomarkers of redox status should be assessed in athletes with UUPS. Clearly, the micronutrient status of an athlete will deteriorate with a 
reduction in fruits, vegetables or the omission of any food group. Nutritional deficiencies are a cause of fatigue and should be considered as part of the examination of the athlete presenting with fatigue and UUPS. To our knowledge, no published data exist on the micronutrient status of athletes diagnosed with UUPS.

To summarise, the quality of the diet is important for short-term and long-term health of the athlete, with a diet lacking in the basic components comprising recovery and constituting an increased risk for UUPS, particularly when significant 'stressors' are present or increased. A failure to appropriately periodise and individualise the nutritional support, and monitor the athlete effectively throughout the season further increases the risk of UUPS. Finally, it is noteworthy that young athletes with a history of UUPS report loss of appetite with periods of heavy training; ${ }^{10}$ emphasising the importance of periodised nutrition plans, monitoring, education and guidance in prevention.

\section{An exercise physiologist's perspective}

Typically, the literature around the physiology of OR, NFOR and OTS/UUPS begins with an explanation of the stress-recovery-adaptation curve, first described in the seminal work of Seyle ${ }^{84}$ with many variations on this fundamental principle since then. Meeusen $e t a l^{2}$ bring together a summary of aspects of the literature, system by system, alluding to the fact that the stress-recovery-adaptation curve is too general and the diagnosis of UUPS requires a process of exclusion, beginning in the clinic and extending to the sports science team to take into account non-clinical aspects including training volume, EB and nutrition, recovery habits, and psychology.

A major 'input' into the athlete's capacity to recover and adapt is the dose of training, taking into account intensity, duration and frequency. Anecdotally, high performance athletes with a detailed and individualised training plan and regular indicators of progress to inform the training and recovery process may be protected to some degree from UUPS. Unpublished data from British Cycling (Leeder) indicates that UUPS is generally absent from the GB Olympic squad athletes in recent years (presented at the British Association of Sport and Exercise Medicine Spring Conference 2014: http://blogs.bmj.com/bjsm/2014/04/16/the-fatiguedathlete-and-red-s-lessons-from-the-field-and-the-basemspring-conference-2/); however, those without the support of an effective sports science and medicine team are vulnerable.

Meeusen's position stand recognises that the intensification of training is often concurrent with the development of fatigue. ${ }^{2}$ The contrasting metabolism of low-intensity vs high-intensity exercise is fundamental to this. It is well described that fat oxidation rates peak at $\sim 60 \%$ to $65 \%$ of maximal oxygen consumption $\left(\mathrm{VO}_{2} \max \right)$ and once blood lactate is accumulating, fat metabolism dramatically diminishes and may be negligible above $90 \%$ of $\mathrm{VO}_{2}$ max in favour of carbohydrate to fuel a high ATP turnover and maintain workload. ${ }^{85}$ This has significant implications for glycogen use, recovery duration and, therefore, EB. Furthermore, training at altitude or in the heat will further increase glycogen turnover and decrease exercise efficiency, ${ }^{86}$ as will training in a fatigued or depleted state. ${ }^{87}$ Accordingly, consideration should be given to the contrasting metabolic demands of training sessions when designing a training programme. Assisting coaches and athletes to progress training appropriately to avoid UUPS by managing periods of OR is a key role of the sports physiologist.

Training and redox homoeostasis may be an important feature of the stress-adaptation response through the process of hormesis, ${ }^{88}$ although again few data relating to redox homoeostasis exist in elite athletes with UUPS. ${ }^{81}$ It is possible that there is an optimum 'dose' of exercise and associated production of reactive oxygen and nitrogen species that results in adaptation (see Vollard et $\left.a l^{89}\right)$. A recent study of OR over 6 weeks demonstrated an increase in OS with cumulative overload, apparently overwhelming antioxidant defence system by week $6 .{ }^{90}$ Additionally, in functionally overreached state (F-OR), a taper will result in supercompensation and an expected level of performance.

UUPS also has implications for the taper. In an elegant study, Aubry et al. ${ }^{91}$ demonstrated that athletes in a F-OR, performed worse after a 2-week taper than a similar group defined as acutely fatigued from training. This highlights the importance of training management, and adds weight to the notion that 2 weeks should be adequate for a positive improvement in performance. Even in the F-OR group, there was a small increase in performance with a taper that would be absent in UUPS.

The assessment of heart rate variability may be an attractive option for preventing UUPS in endurance athletes; however, the data in this area are sparse. A recent study of trained triathletes demonstrated that in F-OR, a progressive tendency towards parasympathetic modulation of heart rate was evident. The study concluded that the heart rate variability should be assessed on a daily basis to account for noise in the signal. ${ }^{92}$ Together with many other considerations, the appropriate management and monitoring of workload and recovery is fundamental to the avoidance of UUPS. Various software exist that track training volume, and there are examples that use algorithms to yield an index of overall recovery; however, to our knowledge, none of these have been validated. However, a battery of monitoring tools could be effective in avoiding UUPS, including the measurement of physiological and psychological variables, together with logs of dietary and training practices.

It is recognised that key to the training and adaptation cycle is energy homoeostasis. Indeed the IOC has recently introduced a new term: Relative Energy Deficiency in Sport (RED-S ${ }^{20}$ ) that implicates energy 
deficiency in a host of pathologies, underperformance problems and conditions, including the Female Athlete Triad, but not restricted to female athletes. Further, RED-S is implicated in a range of symptoms associated with the diagnosis of UUPS including decreased endurance performance and decreased training response. Energy homoeostasis can be assessed globally through changes in body weight and body composition; however, biomarkers of energy homoeostasis may also be of use including hormones, peptides and cytokines, comprehensively reviewed by Jürimäe $e t a l .^{93}$

The other major component of the stress-recovery-adaptation is of course recovery and sports physiologists have strived to offer techniques of promoting or enhancing recovery in athletes, including (in addition to nutritional interventions described above) compression, ${ }^{94}$ cold water immersion ${ }^{95}$ and sleep. ${ }^{24}$ Evidence that athletes with UUPS are failing to achieve sufficient sleep (quality and quantity) is absent from the literature. However, sleep remains a cause for concern, particularly given the clear and growing association between sleep deprivation and a range of negative associations including compromised immune function; ${ }^{96}$ compromised daytime performance $;{ }^{97}$ and generally lower quality and quantity of sleep in elite athletes compared with healthy non-athlete controls. ${ }^{98}$ Furthermore, one recent study using wristwatch actigraphy assessed sleep in the F-OR athlete, observing a significant decrease in sleep duration, sleep efficiency and immobile time during sleep $(-7.9 \%,-1.6 \%$ and $-7.6 \%$, respectively ${ }^{99}$ ), implying that chronic sleep deprivation could be a critical factor in the aetiology of UUPS.

\section{A sports psychologist's perspective}

Building from Meeusen $e t a l^{2}$ and from a psychological perspective, the first thing to notice is the recovery time factor which seems to be inherent in distinguishing between F-OR, NFOR and OTS; most particularly the stagnation factor associated with NFOR and therefore, presumably, OTS. Indeed, this led Meeusen and colleagues to use the term 'prolonged maladaptation' as a distinguishing characteristic between these various forms. For practitioners, this emphasises the importance of athlete perception as an important discriminating factor, perhaps even more important than actual physical training load (cf. Birrer et $a t^{6}$ ), between who does or does not suffer with these problems. Certainly, in the absence of the clear test for UUPS which has been suggested, perception seems to be one of several factors which, rather than discriminating by degree, may be either cause or symptom, depending on the individual.

The other factor worthy of mention from Meeusen $e t a l^{2}$ is the coaction and impact of psychology, over and above the well-examined mood state profiling which has dominated the literature. Meeusen $e t a l^{2}$ provide a good coverage of this literature, together with the pitfalls of mood as an OTS indicator (eg, need for consistent protocols, faking by athletes, consistency of self-report, etc).
What is less apparent, however, is the effect that this state (however protracted) will have on other markers, including hormonal levels, performance tests, etc. As such, psychology is clearly more than just mood and has a plethora of interactive effects; indeed, it is this that underpins the promise of perceived measures (eg, RPE, muscle soreness ${ }^{100}{ }^{101}$ ) as preventative tests.

Indeed, recent work (eg, Cook and Beaven ${ }^{102}$ ) supports this contention on the role of perception as a cause of incidence or prevention, particularly on the delicate edge where the system can go either way. In any case, it seems fair to suggest that perception of the challenge and how close it is to your limits is an important concomitant which practitioners should monitor and, where possible, employ. Other studies have highlighted psychological traits (eg, optimism; ${ }^{103}$ self-determined motivation ${ }^{104}$ ) and states (eg, the switch in perception to external factors when fatigued; ${ }^{104}$ self-esteem ${ }^{105}$ ), which also seem to mediate the impact of physical challenges.

Certainly, as our understanding of stress extends from the homoeostasis position of Selyé towards the new allostatic perspective (eg, McEwen ${ }^{106}$ ), that the importance of such complex interactions between psychological and physiological factors becomes clear as they can account for the varied responses which characterise UUPS and similar conditions. ${ }^{107}$ Certainly, the integrated model suggested by Grove et $a l^{108}$ in dance provides a good basis for applied work across other performance domains. A list of presetting conditions (both environmental and personality), antecedents and a mechanistic interaction of factors provides the structure by which practitioners can address the issue. In this regard, it is worth highlighting that non-training factors seem to have a clear association with UUPS, albeit (unsurprisingly) only in some cases. ${ }^{109}$ The ideas presented in this model on entrapment and restraining factors (relating, perhaps to a perceived lack of control) also hold some promise although, clearly and commonly, more research is needed. In simple terms, we know lots but discerning the exact blend to apply to any individual case remains a complex challenge, ${ }^{4}$ despite high-quality medical research, which is uncovering some of the mechanisms that seem to occur in some of the cases. ${ }^{110}$

In fact, the clearest and most significant point is the highly individualised nature of these complaints. In short, and as with so many human factors, ${ }^{111}$ a particular intraindividual blend of biopsychosocial elements is associated with the susceptibility to, and incidence of, UUPS. ${ }^{6}$ This inherent variability may well explain the use of OTS as a 'diagnostic dustbin' and the extreme variation in precursors and outcomes seem, to us, a likely part of the reconsideration of OTS as UUPS. ${ }^{34}$

Thus, these varied precursors, concomitants and outcomes point to the need for interdisciplinary and personalised support. Perhaps the best preventative strategy lies with coaches and support staff, who have good knowledge of the athletes, employing a variety of 
different and personalised markers, as is now often the case with daily monitoring for training readiness. ${ }^{48} 112$ In simple terms, the initial use of a broad testing spectrum, followed by a personalised refinement based on which markers appear most reactive to each individual, would seem the best general rule for progress. Further reflecting the psychological dimension, a focus on athlete perception as a sound general approach is to be encouraged; ensuring that athletes know what, why and when they are doing things and that they have confidence in the plan. Increased coach-athlete discussion, surely a sensible procedure across the development spectrum, is a major tool in this approach.

Finally, it is of utmost importance to "know your athlete! What s/he thinks of the specific training, why $\mathrm{s} /$ he thinks that and, more broadly, their general disposition (eg, optimistic/pessimistic, high/low trait anxious, etc). The bottom line being, changing perceptions (although often easier said than done) can have a significant effect.

\section{CONCLUSION}

The coach and interdisciplinary team strive to continually progress the athlete's performance year on year. In structuring the annual training programme, coaches and scientists are planning distinct periods of progressive overload coupled with recovery for anticipated performances to be delivered on fixed dates of competition in the calendar year, for example, World Championships and Olympic Games. Should the devised period of overload training be too great for a given athlete leading into a precompetition taper, ${ }^{91}$ or tapering insufficient for super compensation, then the window of opportunity to perform optimally has passed, or worse, a period of UUPS ensues. Peaking at major championships is a challenge, and training capacity is highly individual, with fine margins between the training dose necessary for adaptation and that which elicits maladaptation at the elite level. Thus, monitoring of the athlete's progression through periods of physical preparation (ie, microcycles and macrocycles) is crucial to understanding whether s/ he is on plan (ie, performing and fatigued states managed). Ensuring that training and environmental stresses are appropriate is also crucial, recognising these will change year on year. Indeed, across the training cycle, there will be periods when the athletes training load, nutritional and psychological support require necessary adjustment (ie, optimisation) to stay on track. Such an approach requires a multidisciplinary structured monitoring programme providing knowledge of which variables to monitor (biochemical, psychological, physiological and non-exhausting physical tests, eg, five-bound test ${ }^{113}$ ), and when to test the athlete and capture data (eg, point in the training cycle; at rest; during or after controlled exercise; in the field or laboratory), thus directing the scientist and practitioner as to when to intervene to stay on plan. An additional benefit to regular monitoring is an increase in communications between the athlete, coach and sports science team, with the data driving purposeful conversations. That said, although a proactive and preventative approach is clearly favoured and feasible with monitoring and collection of athlete data, a retrospective analysis can still inform future athlete management and refinement of the monitoring programme can be used to explain episodes of underperformance. Furthermore, obtaining a well-controlled baseline for all monitoring variables is recommended, supporting the establishment of individual athlete reference data and quantification of intraindividual variation and meaningful changes. Finally, a spectrum of monitoring variables are necessary in the athletes programme, on the basis that no single variable has proven effective at identifying UUPS in all studies ${ }^{214}$ (ie, athletes and sports), with the utility of certain monitoring variables resulting from differences in (but not exclusive to) biochemical individuality, gender, sport, training age, training status, and the reliability and reproducibility of the analytical approaches.

\section{Author affiliations}

${ }^{1}$ ORRECO Ltd, Institute of Technology, Sligo, Ireland

${ }^{2}$ English Institute of Sport, Bath, UK

${ }^{3}$ School of Sport, Health and Applied Science, St Mary's University,

Twickenham, London, UK

${ }^{4}$ Institute of Coaching and Performance (ICAP), University of Central Lancashire, Preston, UK

${ }^{5}$ Grey Matters Performance Ltd., Preston, UK

${ }^{6}$ University Hospital of South Manchester NHS Foundation Trust, Manchester, UK

Competing interests None declared.

Provenance and peer review Not commissioned; internally peer reviewed.

Open Access This is an Open Access article distributed in accordance with the Creative Commons Attribution Non Commercial (CC BY-NC 4.0) license, which permits others to distribute, remix, adapt, build upon this work noncommercially, and license their derivative works on different terms, provided the original work is properly cited and the use is non-commercial. See: http:// creativecommons.org/licenses/by-nc/4.0/

\section{REFERENCES}

1. Meeusen R, Duclos M, Gleeson M, et al. Prevention, diagnosis and treatment of the overtraining syndrome. Eur J Sport Sci 2006;6:1-14.

2. Meeusen R, Duclos M, Foster C, et al., European College of Sport Science; American College of Sports Medicine. Prevention, diagnosis, and treatment of the overtraining syndrome: joint consensus statement of the European College of Sport Science and the American College of Sports Medicine. Med Sci Sports Exerc 2013:45:186-205.

3. Budgett R. Overtraining and chronic fatigue: the unexplained underperformance syndrome (UPS). Int Sport Med J 2000;1.

4. Budgett R, Newsholme E, Lehmann M, et al. Redefining the overtraining syndrome as the unexplained underperformance syndrome. Br J Sports Med 2000;34:67-8.

5. Halson SL, Jeukendrup AE. Does overtraining exist? An analysis of overreaching and overtraining research. Sports Med 2004:34:967-81.

6. Birrer D, Lienhard D, Williams CA, et al. Prevalence of non-functional overreaching and the overtraining syndrome in Swiss elite athletes. Schweiz Z Sportmedizin Sporttraumatol 2013;61:23-29.

7. Koutedakis Y, Craig Sharp NC. Seasonal variations of injury and overtraining in elite athletes. Clin J Sport Med 1998;8:18. 
8. Kenttä G, Hassmén P, Raglin JS. Training practices and overtraining syndrome in Swedish age-group athletes. Int $J$ Sports Med 2001;22:460-5.

9. Kuipers H. Training and overtraining: an introduction. Med Sci Sports Exerc 1998;30:1137-9.

10. Matos NF, Winsley RJ, Williams CA. Prevalence of nonfunctional overreaching/overtraining in young English athletes. Med Sci Sports Exerc 2011;43:1287-94.

11. Morgan WP, O'Connor PJ, Sparling PB. Psychological characterization of the elite female distance runner. Int J Sports Med 1987;8(Suppl 2):124-31.

12. Derman W, Schwellnus MP, Lambert MI, et al. The "worn-out athlete": a clinical approach to chronic fatigue in athletes. J Sports Sci 1997;15:341-51.

13. Halson SL. Monitoring training load to understand fatigue in athletes. Sports Med 2014;44:139-47.

14. Urhausen A, Kindermann W. Diagnosis of overtraining: what tools do we have? Sports Med 2002;32:95-102.

15. Halson SL, Lancaster GI, Achten J, et al. Effects of carbohydrate supplementation on performance and carbohydrate oxidation after intensified cycling training. J Appl Physiol 2004;97:1245-53.

16. Achten J, Halson SL, Moseley L, et al. Higher dietary carbohydrate content during intensified running training results in better maintenance of performance and mood state. J Appl Physiol 2004;96:1331-40.

17. Vanheest JL, Rodgers CD, Mahoney CE, et al. Ovarian suppression impairs sport performance in junior elite female swimmers. Med Sci Sports Exerc 2014;46:156-66.

18. Garthe I, Raastad T, Refsnes PE, et al. Effect of two different weight-loss rates on body composition and strength and power-related performance in elite athletes. Int J Sport Nutr Exerc Metab 2011;21:97-104.

19. Haakonssen EC, Martin DT, Burke LM, et al. Increased lean mass with reduced fat mass in an elite female cyclist returning to competition: case study. Int J Sports Physiol Perform 2013;8:699-701.

20. Mountjoy M, Sundgot-Borgen J, Burke L, et al. The IOC consensus statement: beyond the Female Athlete Triad-Relative Energy Deficiency in Sport (RED-S). Br J Sports Med 2014;48:491-7.

21. Mountjoy M, Sundgot-Borgen J, Burke L. Authors' 2015 additions to the IOC consensus statement: Relative Energy Deficiency in Sport (RED-S). Br J Sports Med 2015;49:417-20.

22. Bartlett JD, Hawley JA, Morton JP. Carbohydrate availability and exercise training adaptation: too much of a good thing? Eur J Sport Sci 2015;15:3-12.

23. Bartlett JD, Louhelainen J, lqbal Z, et al. Reduced carbohydrate availability enhances exercise-induced p53 signaling in human skeletal muscle: implications for mitochondrial biogenesis. $A m \mathrm{~J}$ Physiol Regul Integr Comp Physiol 2013;304:R450-8.

24. Halson SL. Sleep in elite athletes and nutritional interventions to enhance sleep. Sports Med 2014;44:13-23.

25. Afaghi A, O'Connor H, Chow CM. High-glycemic-index carbohydrate meals shorten sleep onset. Am J Clin Nutr 2007;85:426-30.

26. Witard OC, Jackman SR, Kies AK, et al. Effect of increased dietary protein on tolerance to intensified training. Med Sci Sports Exerc 2011;43:598-607.

27. Yeo WK, Paton CD, Garnham AP, et al. Skeletal muscle adaptation and performance responses to once a day versus twice every second day endurance training regimens. J Appl Physiol 2008;105:1462-70.

28. Drust B, Morton J. Promoting endurance training adaptations with nutritional interventions: the potential benefits of 'low carbohydrate' training. Kineziologija 2009;41:19-24.

29. Stellingwerff T. Contemporary nutrition approaches to optimize elite marathon performance. Int J Sports Physiol Perform 2013;8:573-8.

30. Hawley JA, Burke LM. Carbohydrate availability and training adaptation: effects on cell metabolism. Exerc Sport Sci Rev 2010;38:152-60

31. Van Proeyen K, Szlufcik K, Nielens H, et al. Beneficial metabolic adaptations due to endurance exercise training in the fasted state. J Appl Physiol 2011;110:236-45.

32. Stellingwerf T. Case study: nutrition and training periodization in three elite marathon runners. Int J Sport Nutr Exerc Metab 2012;22:392-400.

33. Robson PJ. Elucidating the unexplained underperformance syndrome in endurance athletes. Sports Med 2003;33:771-81.

34. Lakier Smith L. Overtraining, excessive exercise, and altered immunity: is this a T helper-1 versus T helper-2 lymphocyte response? Sports Med 2003;33:347-64.
35. Pedersen BK, Febbraio MA. Muscle as an endocrine organ: focus on muscle-derived interleukin-6. Physiol Rev 2008:88:1379-406.

36. Robson-Ansley PJ, de Milander L, Collins M, et al. Acute interleukin-6 administration impairs athletic performance in healthy, trained male runners. Can J Appl Physiol 2004;29:411-18.

37. Cox AJ, Pyne DB, Saunders PU, et al. Cytokine responses to treadmill running in healthy and illness-prone athletes. Med Sci Sports Exerc 2007;39:1918-26.

38. Walsh NP, Gleeson M, Pyne DB, et al. Position statement. Part two: maintaining immune health. Exerc Immunol Rev 2011;17:64-103

39. Lemon PW, Mullin JP. Effect of initial muscle glycogen levels on protein catabolism during exercise. J Appl Physiol Respir Environ Exerc Physiol 1980;48:624-9.

40. Howarth KR, Phillips SM, MacDonald MJ, et al. Effect of glycogen availability on human skeletal muscle protein turnover during exercise and recovery. J Appl Physiol 2010;109:431-8.

41. Gleeson M, Blannin AK, Walsh NP, et al. Effect of low- and high-carbohydrate diets on the plasma glutamine and circulating leukocyte responses to exercise. Int J Sport Nutr 1998:8:49-59.

42. Parry-Billings $M$, Budgett $R$, Koutedakis $Y$, et al. Plasma amino acid concentrations in the overtraining syndrome: possible effects on the immune system. Med Sci Sports Exerc 1992;24:1353-8.

43. Kingsbury KJ, Kay L, Hjelm M. Contrasting plasma free amino acid patterns in elite athletes: association with fatigue and infection. $\mathrm{Br} J$ Sports Med 1998;32:25-32, discussion32-3.

44. Phillips SM. Dietary protein requirements and adaptive advantages in athletes. BJN 2012;108:S158-67.

45. Phillips SM, Van Loon LJ. Dietary protein for athletes: from requirements to optimum adaptation. J Sports Sci 2011;29(Suppl 1):S29-38.

46. Machinnon LT, Hooper SL. Plasma glutamine and upper respiratory tract infection during intensified training in swimmers. Med Sci Sports Exerc 1996;28:285-90.

47. Halson SL, Lancaster G, Jeukendrup AE, et al. Immunological responses to overreaching in cyclists. Med Sci Sports Exerc 2003;35:854-61.

48. Coutts AJ, Reaburn P, Piva TJ, et al. Monitoring for overreaching in rugby league players. Eur J Appl Physiol 2007;99:313-24.

49. Smith DJ, Norris SR. Changes in glutamine and glutamate concentrations for tracking training tolerance. Med Sci Sports Exerc 2000;32:684-9.

50. Witard OC, Turner JE, Jackman SR, et al. High dietary protein restores overreaching induced impairments in leukocyte trafficking and reduces the incidence of upper respiratory tract infection in elite cyclists. Brain Behav Immun 2014;39:211-19.

51. Kraemer WJ, Ratamess NA, Volek JS, et al. The effects of amino acid supplementation on hormonal responses to resistance training overreaching. Metabolism 2006:55:282-91.

52. Margonis K, Fatouros IG, Jamurtas AZ, et al. Oxidative stress biomarkers responses to physical overtraining: Implications for diagnosis. Free Radic Biol Med 2007;43:901-10.

53. Tanskanen M, Atalay M, Uusitalo A. Altered oxidative stress in overtrained athletes. J Sports Sci 2010;28:309-17.

54. Tanskanen M, Uusitalo A, Kinnunen $\mathrm{H}$, et al. Association of military training with oxidative stress and overreaching. Med Sci Sports Exerc 2011;43:1552-60.

55. Vecchiet J, Cipollone F, Falasca K, et al. Relationship between musculoskeletal symptoms and blood markers of oxidative stress in patients with chronic fatigue syndrome. Neurosci Lett 2003;335:151-4

56. Kennedy G, Spence VA, McLaren M, et al. Oxidative stress levels are raised in chronic fatigue syndrome and are associated with clinical symptoms. Free Radic Biol Med 2005;39:584-9.

57. Richards RS, Roberts TK, McGregor NR, et al. Blood parameters indicative of oxidative stress are associated with symptom expression in chronic fatigue syndrome. Redox Rep 2000;5:35-41.

58. Jammes $Y$, Steinberg JG, Delliaux S. Chronic fatigue syndrome: acute infection and history of physical activity affect resting levels and response to exercise of plasma oxidant/antioxidant status and heat shock proteins. J Intern Med 2012;272:74-84.

59. Jammes Y, Steinberg JG, Delliaux S, et al. Chronic fatigue syndrome combines increased exercise-induced oxidative stress and reduced cytokine and Hsp responses. J Intern Med 2009;266:196-206.

60. Jammes Y, Steinberg JG, Mambrini O, et al. Chronic fatigue syndrome: assessment of increased oxidative stress and altered muscle excitability in response to incremental exercise. J Intern Med 2005;257:299-310.

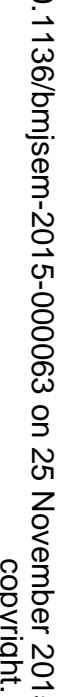


61. Fulle $\mathrm{S}$, Mecocci $\mathrm{P}$, Fanò $\mathrm{G}$, et al. Specific oxidative alterations in vastus lateralis muscle of patients with the diagnosis of chronic fatigue syndrome. Free Radic Biol Med 2000;29:1252-9.

62. Robinson M, Gray SR, Watson MS, et al. Plasma IL-6, its soluble receptors and F2-isoprostanes at rest and during exercise in chronic fatigue syndrome. Scand J Med Sci Sports 2010;20:282-90.

63. Watson TA, Callister R, Taylor RD, et al. Antioxidant restriction and oxidative stress in short-duration exhaustive exercise. Med Sci Sports Exerc 2005;37:63-71.

64. Plunkett BA, Callister R, Watson TA, et al. Dietary antioxidant restriction affects the inflammatory response in athletes. BJN 2009;103:1179-84.

65. Howatson G, Howatson G, McHugh MP, et al. Influence of tart cherry juice on indices of recovery following marathon running. Scand J Med Sci Sports 2009;20:843-52.

66. Bell P, Walshe I, Davison G, et al. Montmorency cherries reduce the oxidative stress and inflammatory responses to repeated days high-intensity stochastic cycling. Nutrients 2014;6: 829-43.

67. Myburgh KH, Kruger MJ, Smith C. Accelerated skeletal muscle recovery after in vivo polyphenol administration. $J$ Nutr Biochem 2012;23:1072-9.

68. Kruger MJ, Smith C. Postcontusion polyphenol treatment alters inflammation and muscle regeneration. Med Sci Sports Exerc 2012;44:872-80.

69. Howatson G, Bell PG, Tallent J, et al. Effect of tart cherry juice (Prunus cerasus) on melatonin levels and enhanced sleep quality. Eur J Nutr 2012;51:909-16.

70. Myburgh $\mathrm{KH}$. Polyphenol supplementation: benefits for exercise performance or oxidative stress? Sports Med 2014;44:57-70.

71. Grobler LA, Collins M, Lambert MI, et al. Skeletal muscle pathology in endurance athletes with acquired training intolerance. $\mathrm{Br} J$ Sports Med 2004;38:697-703.

72. Labazi M, McNeil AK, Kurtz T, et al. The antioxidant requirement for plasma membrane repair in skeletal muscle. Free Radic Biol Med 2015;84:246-53.

73. Mullins VA, Houtkooper LB, Howell WH, et al. Nutritional status of U.S. elite female heptathletes during training. Int J Sport Nutr Exerc Metab 2001:11:299-314.

74. Tomten SE, Høstmark AT. Serum vitamin E concentration and osmotic fragility in female long-distance runners. J Sports $\mathrm{SCl}$ 2009;27:69-76.

75. Slattery KM, Coutts AJ, Wallace LK. Nutritional practices of elite swimmers during an intensified training camp: with particular reference to antioxidants. J Sports Med Phys Fitness 2012;52:501-5.

76. Ney JG, Koury JC, Azeredo VB, et al. Associations of n-6 and n-3 polyunsaturated fatty acids and tocopherols with proxies of membrane stability and subcutaneous fat sites in male elite swimmers. Nutr Res 2009;29:623-30.

77. Bailey DM, Lawrenson L, McEneny J, et al. Electron paramagnetic spectroscopic evidence of exercise-induced free radical accumulation in human skeletal muscle. Free Radic Res 2007:41:182-90.

78. Pialoux V, Brugniaux JV, Rock E, et al. Antioxidant status of elite athletes remains impaired 2 weeks after a simulated altitude training camp. Eur J Nutr 2010;49:285-92.

79. Pialoux V, Mounier R, Rock E, et al. Effects of the "live high-train low" method on prooxidant/antioxidant balance on elite athletes. Eur J Clin Nutr 2009;63:756-62.

80. Pialoux V, Mounier R, Brugniaux JV, et al. Thirteen days of "live high-train low" does not affect prooxidant/antioxidant balance in elite swimmers. Eur J Appl Physiol 2009;106:517-24.

81. Lewis NA, Howatson G, Morton K, et al. Alterations in redox homeostasis in the elite endurance athlete. Sports Med 2015;45:379-409.

82. van Wijck K, Lenaerts K, Grootjans J, et al. Physiology and pathophysiology of splanchnic hypoperfusion and intestinal injury during exercise: strategies for evaluation and prevention. $A m \mathrm{~J}$ Physiol Gastrointest Liver Physiol 2012;303:G155-68.

83. Ashton T, Young I, Davison G, et al. Exercise-induced endotoxemia: the effect of ascorbic acid supplementation. Free Radic Biol Med 2003;35:284-91.

84. Selye $\mathrm{H}$. Stress and the general adaptation syndrome. BM 1950;1:1383-92.

85. Achten J, Jeukendrup AE. Maximal fat oxidation during exercise in trained men. Int J Sports Med 2003;24:603-8.
86. Jentjens RL, Wagenmakers AJ, Jeukendrup AE. Heat stress increases muscle glycogen use but reduces the oxidation of ingested carbohydrates during exercise. J Appl Physiol 2002;92:1562-72.

87. Lazzer S, Salvadego D, Rejc E, et al. The energetics of ultra-endurance running. Eur J Appl Physiol 2012;112:1709-15.

88. Radak Z, Chung HY, Koltai E, et al. Exercise, oxidative stress and hormesis. Ageing Res Rev 2008;7:34-42.

89. Vollard NB, Shearman JP, Cooper CE. Exercise-induced oxidative stress: myths, realities and physiological relevance. Sports Med 2005;35:1045-62.

90. Knez WL, Jenkins DG, Coombes JS. The effect of an increased training volume on oxidative stress. Int J Sports Med 2014;35:8-13.

91. Aubry A, Hausswirth C, Louis J, et al. Functional overreaching. Med Sci Sports Exerc 2014;46:1769-77.

92. Le Meur Y, Pichon A, Schaal K, et al. Evidence of parasympathetic hyperactivity in functionally overreached athletes. Med Sci Sports Exerc 2013;45:2061-71.

93. Jürimäe J, Mäestu J, Jürimäe $T$, et al. Peripheral signals of energy homeostasis as possible markers of training stress in athletes: a review. Metabolism 2011;60:335-50.

94. Hill J, Howatson $\mathrm{G}$, van Someren $\mathrm{K}$, et al. Compression garments and recovery from exercise-induced muscle damage: a meta-analysis. Br J Sports Med 2014;48:1340-6.

95. Leeder J, Gissane C, van Someren K, et al. Cold water immersion and recovery from strenuous exercise: a meta-analysis. $\mathrm{Br} J$ Sports Med 2012;46:233-40.

96. Cohen S, Doyle WJ, Alper CM, et al. Sleep habits and susceptibility to the common cold. Arch Intern Med 2009;169:62-7.

97. Pejovic S, Basta M, Vgontzas AN, et al. Effects of recovery sleep after one work week of mild sleep restriction on interleukin-6 and cortisol secretion and daytime sleepiness and performance. Am J Physiol Endocrinol Metab 2013;305:E890-6.

98. Leeder J, Glaister M, Pizzoferro K, et al. Sleep duration and quality in elite athletes measured using wristwatch actigraphy. J Sports Sci 2012;30:541-5.

99. Hausswirth C, Louis J, Aubry A, et al. Evidence of disturbed sleep and increased illness in overreached endurance athletes. Med Sci Sports Exerc 2014;46:1036-45.

100. Foster C. Monitoring training in athletes with reference to overtraining syndrome. Med Sci Sports Exerc 1998;30:1164-8.

101. Hooper SL, Mackinnon LT. Monitoring overtraining in athletes. Recommendations. Sports Med 1995;20:321-7.

102. Cook CJ, Beaven CM. Individual perception of recovery is related to subsequent sprint performance. Br J Sports Med 2013;47:705-9.

103. Gustafsson $\mathrm{H}$, Skoog T. The mediational role of perceived stress in the relation between optimism and burnout in competitive athletes. Anxiety Stress Coping 2012;25:183-99.

104. Lemyre PN, Roberts GC. Motivation, overtraining, and burnout: Can self-determined motivation predict overtraining and burnout in elite athletes? Eur J 2007;7:115-132

105. Clow A, Hucklebridge F. The impact of psychological stress on immune function in the athletic population. Exerc Immunol Rev 2001;7:5-17.

106. McEwen BS. Stress, adaptation, and disease. Allostasis and allostatic load. Ann N Y Acad Sci 1998;840:33-44.

107. Polman R, Houlahan K. A cumulative stress and training continuum model: a multidisciplinary approach to unexplained underperformance syndrome. Res Sports Med 2004;12:301-316.

108. Grove JR, Main LC, Sharp L. Stressors, recovery processes, and manifestations of training distress in dance. J Dance Med Sci 2013;17:70-8.

109. Meehan HL, Bull SJ, Wood DM. The overtraining syndrome: a multicontextual assessment. Psychologist 2004.

110. Budgett R, Hiscock N, Arida RM, et al. The effects of the 5-HT2C agonist $\mathrm{m}$-chlorophenylpiperazine on elite athletes with unexplained underperformance syndrome (overtraining). $\mathrm{Br} \mathrm{J}$ Sports Med 2010;44:280-3.

111. Skinner JS, Jaskólski A, Jaskólska A, et al. Age, sex, race, initial fitness, and response to training: the HERITAGE Family Study. J Appl Physiol 2001;90:1770-6.

112. Coutts A, Wallace L, Slattery K. Monitoring changes in performance, physiology, biochemistry, and psychology during overreaching and recovery in triathletes. Int J Sports Med 2007;28:125-34.

113. Coutts AJ, Slattery KM, Wallace LK. Practical tests for monitoring performance, fatigue and recovery in triathletes. J Sci Med Sport 2007;10:372-81. 